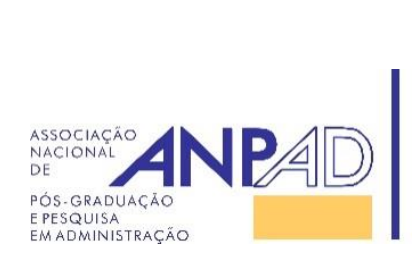

Disponível em

http://rac.anpad.org.br

RAC, Rio de Janeiro, v. 22, n. 5, art. 4,

pp. 704-725, setembro/outubro, 2018

http://doi.org/10.1590/1982-7849rac2018170281

\title{
Integração Vertical em Montadoras Automotivas
}

\author{
Vertical Integration in Automakers
}

Cleiciele Albuquerque Augusto ${ }^{1}$

(iD) https://orcid.org/0000-0001-5416-3217

José Paulo de Souza ${ }^{1}$

iD https://orcid.org/0000-0002-5659-1044

Silvio Antonio Ferraz Cario ${ }^{2}$

https://orcid.org/0000-0002-0601-5663

Universidade Estadual de Maringá, Departamento de Administração, Maringá, PR, Brasil ${ }^{1}$ Universidade Federal de Santa Catarina, Departamento de Ciências Econômicas, Florianópolis, SC, Brasil ${ }^{2}$ 


\title{
Resumo
}

O objetivo no presente artigo foi compreender a escolha da integração vertical em montadoras de veículos automotivos, considerando a presença de custos de transação, de mensuração e de recursos estratégicos. Para tanto, um estudo de casos múltiplos de natureza qualitativa e do tipo descritivo foi realizado a partir de entrevistas semiestruturadas com agentes de três montadoras automotivas e da Federação das Indústrias do Estado do Paraná (FIEP). A proposição de complementaridade formulada considerou que a integração vertical é decorrente da presença de ativos específicos, influenciada pela dificuldade de mensuração desses ativos e de sua condição de recurso estratégico. Essa proposição foi ratificada, dado que se constatou que a integração vertical se dá para itens como design, estamparia, motor e câmbio, que, além de elevada especificidade, apresentam dificuldade de mensuração (partes internas do motor, do câmbio, e aspectos de design, por exemplo) e se constituem na identidade das montadoras, confirmando a sua condição estratégica. Conclui-se que a complementaridade entre essas concepções teórico-analíticas pode construir um referencial com maior poder de compreensão das escolhas envolvendo estruturas de governança.

Palavras-chave: montadoras automotivas; custos de transação; custos de mensuração; recursos estratégicos; integração vertical.

\begin{abstract}
In this article the aim was to understand the choice of vertical integration in automakers considering the presence of transaction costs, measurement costs and strategic resources. For this, multiple qualitative-descriptive case studies were carried out using semi-structured interviews in three automakers and the Industrial Federation of the State of Parana (FIEP), all located in the State of Paraná. The proposition of formulated complementarity considered that vertical integration is due to the presence of specific assets, influenced by the difficulty of measuring them, and their importance as strategic resources. This proposition was ratified, as we found that vertical integration occurs for items such as design, stamping, motor, and transmission, which have high specificity, are difficult to measure (internal engine parts, transmission, and design aspects, for example) and constitute automaker identity, which confirms their strategic importance. We concluded that the complementarity between these theoretical-analytical conceptions can build a referential with greater power for understanding choices involving governance structures.
\end{abstract}

Keywords: automakers; transaction costs; measurement costs; strategic resources; vertical integration.

JEL codes: F15, N36, L62. 


\section{Introdução}

Movimentos de integração e desintegração vertical marcaram a história do desenvolvimento do setor automotivo. Nos primeiros momentos da organização industrial automotiva, no início do século XIX, a indústria era desverticalizada, sendo a fabricação de veículos feita através da subcontratação de profissionais qualificados (Costa \& Henkin, 2016; Lung \& Volpato, 2002). Na segunda metade do mesmo século, conforme Lung e Volpato (2002), a organização da produção automotiva foi caracterizada pela integração vertical, por meio da internalização da produção da matéria-prima necessária às suas atividades. Um novo momento, iniciado nos anos 1960, e ainda presente, é marcado pelo retorno à produção desverticalizada, com novos delineamentos na relação montadora-fornecedor (Costa \& Henkin, 2016; Ferreira \& Serra, 2010; Lung \& Volpato, 2002; Torres \& Cario, 2012; Vanalle $\&$ Salles, 2011).

Esses movimentos - de integração e desintegração vertical - geraram estruturas de coordenação distintas nas montadoras automotivas (Costa \& Henkin, 2016; Sacomano \& Iemma, 2004; Toledo, Silva, Alliprandini, Martins, \& Ferrari, 2008, Vanalle \& Salles, 2011). Embora arranjos mais desverticalizados, com participação e dependência de fornecedores, sejam predominantes nos últimos anos, a internalização da fabricação de algumas autopeças, com forte controle pelas montadoras, ainda é encontrada (Ferreira \& Serra, 2010; Lung \& Volpato, 2002; Torres e Cario, 2012; Vanalle \& Salles, 2011). Diante disso, questiona-se: como se dá a decisão pela integração vertical da produção de autopeças no setor automotivo, considerando-se que as decisões no momento atual são orientadas para a desverticalização da produção de autopeças?

As decisões de internalização e externalização da produção podem ser discutidas a partir da abordagem teórica da Nova Economia Institucional (NEI), em que essas decisões configuram diferentes tipos de estruturas de governança - integração vertical, contratação e mercado. Entre as construções da NEI, tomam corpo as abordagens microanalíticas da Teoria dos Custos de Transação (Coase, 1937; Klein, Crawford, \& Alchian, 1978; Williamson, 1975, 1985, 1996; Zylbersztajn, 2009) e da Teoria dos Custos de Mensuração (Barzel, 1997, 2003, 2005; Coase, 1937; Ménard \& Shirlei, 2014; Zylbersztajn, 2009).

Apresentando o objetivo de reduzir custos de transação, a TCT e a TCM orientam a escolha da integração vertical a partir de diferentes pressupostos teóricos. Pela TCT, Williamson $(1975,1985)$ indica que a elevada especificidade do ativo transacionado é o principal atributo influenciador na escolha pela integração vertical, visando à redução de custos de transação. Já pela TCM, Barzel $(2003,2005)$ propõe que essa escolha pela integração se dá em função da dificuldade de mensurar as dimensões dos atributos transacionados, visando garantir direitos de propriedade.

A Visão Baseada em Recursos (VBR) também trata da integração vertical. A VBR indica que são os recursos e as capacidades diferenciadas que uma firma possui e controla que lhe garante a obtenção de vantagens competitivas (Barney, 1991; Penrose, 1959; Peteraf, 1993; Wernerfelt, 1984). Apesar de serem encontrados estudos que tratam da complementaridade da VBR e da TCT (Crook, Combs, Ketchen, \& Aguinis, 2013; K. Foss \& Foss, 2005; Neves, Hamacher, \& Scavarda, 2014; Saes, 2009), ainda não são encontradas discussões que insiram a perspectiva de complementaridade envolvendo a TCT e a VBR, em conjunto com a TCM, na consideração da integração vertical.

Na presente investigação, pressupõe-se que o tratamento isolado das premissas básicas dessas abordagens, ou até mesmo a complementaridade da TCT com a VBR, apesar de apropriada, não é capaz de alcançar uma compreensão adequada dos aspectos envolvidos na escolha pela integração da produção. Isso porque, na TCT e na TCM, o estudo das relações verticais, tratando da alocação e da distribuição de valor entre os agentes, ignora o processo de geração de valor, notadamente em dimensões e ativos de elevada especificidade (K. Foss \& Foss, 2005). A VBR, por sua vez, conforme o autor, embora concentre seu foco na criação de valor, por intermédio do controle de recursos estratégicos, não trata da forma como o valor gerado é distribuído, desconsiderando problemas de organização e gerenciamento desses recursos. 
A identificação dessas limitações teóricas justifica a adoção de uma perspectiva de complementaridade teórica. Empiricamente, diante de um setor descentralizado, torna-se importante entender as justificativas para a escolha da integração vertical para obtenção de alguns componentes nessas organizações. Assim, o objetivo deste $\operatorname{artigo~}^{(1)}$ foi compreender como se dá a integração vertical, considerando a complementaridade dos custos de transação, dos custos de mensuraçãoe dos recursos estratégicos nas montadoras de veículos no Estado do Paraná.

O setor automotivo paranaense, objeto desse estudo, destaca-se por ser o terceiro maior produtor automotivo e por apresentar montadoras de representação mundial (Associação Nacional dos Fabricantes de Veículos Automotores [ANFAVEA], 2016). Ademais, as características transacionais das montadoras indicaram possibilidades de explorar os aspectos teóricos das abordagens em sua complementaridade.

Com a presente investigação, busca-se abrir caminhos para explorar a complementaridade das concepções teórico-analíticas dessas teorias, na tentativa de se construir um referencial com maior poder de compreensão das escolhas sobre estruturas de governança. Para concretizá-la, além dessa introdução, no segundo capítulo apresenta-se o referencial teórico utilizado, com uma breve descrição das abordagens TCT, TCM e VBR, as quais se configuram como base para a construção do modelo teórico de complementaridade, principal contribuição deste estudo. O terceiro capítulo apresenta a metodologia empregada, enquanto o quarto capítulo se dedica à análise dos resultados obtidos. O quinto e o sexto capítulos se referem, respectivamente, às conclusões e às referências utilizadas.

\section{Referencial Teórico}

Produzir internamente ou comprar os itens necessários à composição de um produto (make or buy) são dois extremos ao longo de um caminho de possibilidades que podem ser exploradas via relações contratuais. Nessa investigação, a decisão de produzir ou comprar é discutida a partir de Williamson (1985, 1996), que a trata como estruturas de governança. Segundo esse autor, essas estruturas de governança, relacionadas à forma de coordenação das atividades econômicas, podem ser classificadas pela: (a) compra no mercado; (b) produção própria, via integração vertical (internalização de atividades); (c) forma híbrida (contratos).

Nesse contexto, a integração vertical indica um trade off entre o incentivo de mercado e o controle pela organização. Quando as empresas se afastam dos mercados para a integração, elas perdem em incentivos, relacionados a menores custos e a burocracia, mas ganham em autoridade, o que permite maiores monitoramento e controle de ativos (Crook et al., 2013; Neves et al., 2014; Williamson, 1985; Zylbersztajn, 1995, 2009). Nessa investigação, os fatores influenciadores na decisão pela integração vertical, envolvendo aspectos de incentivo e controle, são caracterizados à luz da TCT, TCM e VBR.

\section{Integração vertical pela ótica da TCT, TCM e VBR}

A TCT tem origem no artigo de Ronald Coase, The Nature of the Firm, em 1937, sendo retomada na década de 1970, com os trabalhos de Oliver E. Williamson $(1975,1985,1996)$. Nessa teoria, os custos de transação, em complemento aos de produção, passam a ser considerados no estudo da firma. Como pressuposto, define-se que esses custos são reduzidos na medida em que ocorre um alinhamento entre as estruturas de governança, os atributos de transação (especificidade de ativos, frequência e incerteza) e os pressupostos comportamentais (racionalidade limitada e oportunismo).

Dentre os atributos de transação, a especificidade de ativos, para Williamson $(1985,1996)$, constitui-se no atributo determinante na escolha da estrutura de governança. Para o autor, ativos específicos são aqueles que perdem valor quando não são destinados para a transação que foram acordados e podem ser classificados em: físicos, dedicados, humanos, temporais, de marca e localização. Na presença deles, a integração vertical se mostra como o arranjo mais eficiente, protegendo os agentes 
contra comportamentos oportunistas e apropriação de quase renda (Klein et al., 1978; Ménard \& Shirlei, 2014; Williamson, 1985).

Nota-se que, o estudo das decisões de integração vertical em montadoras, envolvendo o atributo de especificidade de ativos, não é recente. Na proposição teórica de Klein, Crawford e Alchian (1978), são ilustrados os casos da Ford e da General Motors (GM). Essas empresas optaram por integrar a fabricação de determinadas partes fornecidas como forma de reduzir custos de transação, dada a possibilidade de comportamento oportunista pela apropriação de quase renda. Monteverde e Teece (1982), ao discutirem os movimentos de integração vertical em montadoras americanas, "levantam a hipótese de que as montadoras se integrarão verticalmente quando o processo de produção, amplamente definido, gere know-how especializado e não patenteável" (p. 206, tradução nossa). A TCM também tem sua inspiração no artigo de Coase (1937), sendo estruturada por Barzel (1997, 2003, 2005). A escolha dessa abordagem indica que o nível da dificuldade de mensuração determina a estrutura de governança. Para Barzel $(2003,2005)$, a empresa optaria pela integração vertical quando a dificuldade de mensurar mercadorias transacionadas de alto valor, ou de definir os seus direitos de propriedade, aumentassem os custos de transação. Nessa orientação, problemas de mensuração na relação entre montadoras e fornecedores foram tratados por Barzel (1997), em situações em que as decisões pela integração vertical foram tomadas, notadamente, para a garantia de direitos de propriedade.

A VBR tem sua base na teoria econômica, especialmente com Penrose (1959), em sua obra The theory of the growth of the firm. A partir da visão da firma como um conjunto de recursos, Penrose (1959) buscou compreender o crescimento das empresas e os seus limites. Wernerfelt (1984) parte do trabalho de Penrose (1959) e apresenta essa abordagem pelo acrônimo de Resourced Based View (RBV), focando a empresa a partir de seus recursos distintivos, em contraponto à visão apresentada por Porter (1981), baseada em produtos.

A partir de 1990, a discussão de Wernerfelt recebeu mais atenção quando Prahalad e Hamel (1990) introduziram o conceito de Core Competence, caracterizando-o como o aprendizado coletivo na organização, especialmente em como coordenar diversas habilidades produtivas para gerar um diferencial. As contribuições posteriores de Barney (1991) e Peteraf (1993) buscaram melhor estruturar na abordagem da VBR a partir da identificação de unidade de análise e racional. Para Barney (1991), a unidade de análise é a estratégia resultante da utilização dos recursos, enquanto para Peteraf (1993) é a condição do recurso.

Como racional, Barney (1991) propõe que recursos valiosos e raros gerem vantagem competitiva, e sua condição de imperfeita imitação e substituição estabeleça a condição de sustentação de vantagem competitiva frente aos concorrentes. Para Peteraf (1993), quatro condições são necessárias à sustentação de vantagens competitivas de uma firma: (a) recursos heterogêneos superiores; (b) barreiras ex post à competição; (c) barreiras ex ante à competição; (d) imobilidade dos recursos.

A VBR pressupõe que a posse desses recursos geradores de vantagem competitiva estabelece a heterogeneidade entre as organizações (K. Foss \& Foss, 2005), sendo essa consolidada em suas rotinas e decisões idiossincráticas seguidas ao longo de sua história, ou seja, o seu path dependence (Teece, Pisano, \& Shuen, 1997). Conforme K. Foss e Foss (2005), ao considerar as propostas de Barney (1991) e Peteraf (1993), a condição estratégica do recurso se dá pela sua capacidade de criar e sustentar vantagem competitiva.

Nesse caso, a integração vertical, pela VBR, configura-se no mecanismo de proteção e controle de recursos considerados estratégicos para a geração de renda superior aos concorrentes, mesmo numa situação de equilíbrio econômico (Argyres \& Zenger, 2012). Peteraf (1993) indica que essa geração de não mobilidade de recursos pela integração vertical se justifica para recursos especializados para as necessidades da firma. No caso da indústria automotiva, Sörensen (2006) observa que os recursos estratégicos e as capacidades internas são essenciais para atender as necessidades dos clientes no mercado automotivo, e mesmo aquelas ainda a serem criadas pela empresa, justificando a integração vertical. 


\section{Justificativas para a complementaridade entre a TCT, a TCM e a VBR}

Ao se considerarem os pressupostos básicos de cada abordagem teórica, a presença de três aspectos centrais pode ser identificada na decisão pela integração vertical: ativos específicos (TCT); ativos difíceis de mensurar (TCM); recursos estratégicos (VBR). Assim, além da explicação tradicional de que ativos específicos determinam a integração vertical (Williamson, 1975, 1985), busca-se inserir na análise novos elementos a partir da seguinte proposição geral: $\mathbf{O}$ efeito dos ativos específicos sobre a decisão de integrar verticalmente se dá pela sua dificuldade de mensuração e sua condição de recurso estratégico.

Ao desmembrar essa proposição, a partir das orientações de complementaridade de Bacharach (1989) e Suddaby (2010), as seguintes relações entre as categorias principais devem ser realizadas: (1.1) ativos específicos e dificuldades de mensuração; (1.2) ativos específicos e recursos estratégicos; (1.3) recursos estratégicos e dificuldades de mensuração.

Vale notar que o controle se apresenta como principal característica no tratamento da integração vertical (Williamson, 1985, 1991). Nessa linha, pela TCT, o controle se relaciona à minimização da condição de incerteza, considerando que investimentos especializados foram realizados (Tebboune \& Urquhart, 2016; Williamson, 1991). Zylbersztajn (2009, p. 9) observa que "inesperados choques externos ... podem ter consequências reais imprevistas. Portanto, a incerteza motiva a necessidade de um controle mais intenso".

Já pela TCM, o controle surge como um mecanismo para garantir os direitos de propriedade sobre dimensões difíceis de mensurar (Barzel, 2002, 2005). Barzel (2005) afirma que a integração vertical facilita a transmissão de informação, assegurando o direito de propriedade; posição ratificada por Williamson (1985) que considera que, nessa estrutura, os direitos residuais, ou seja, os direitos de posse do ativo, são assegurados. Para Williamson (1985), investimentos específicos exigem uma estrutura de propriedade unificada. Além disso, a existência de turbulências ambientais competitivas exige que respostas rápidas sejam apresentadas, eficientes apenas pela integração vertical (Williamson, 1991).

Com isso, indica-se se que o controle, por meio da integração vertical, pode possibilitar que as respostas, em condições de incerteza e envolvendo ativos específicos (TCT), além de garantia de direitos de propriedade (TCM), sejam mais concretas. A partir desse racional, pode-se considerar:

Proposição 1.1: Se o ativo apresentar elevada especificidade e, ao mesmo tempo, dificuldades de mensuração, a integração vertical é a estrutura de governança mais eficiente.

Considerando a complementaridade entre a TCT e a VBR, o próprio Williamson (1999) admite que a história da firma e os seus recursos, aspectos destacados pela VBR, influenciam nas estruturas de governança. Nessa perspectiva, Ghoshal e Moran (1996) já afirmavam que as vantagens do controle, pela integração vertical, sobre os mercados, estão relacionadas à tentativa de "alavancar a habilidade humana da organização para tomar a iniciativa, cooperar e aprender" (p. 42, tradução nossa). Ademais, como indica Liu (2016), um ponto chave para a decisão da integração vertical pode ser a realização de investimentos inovadores, especialmente em indústrias em que a inovação intensiva é importante.

Assim, a integração vertical pode ocorrer por apresentar características vantajosas como opção de governança, além de ser definidas por custos de transação, em aspectos de controle (Barney \& Hesterly, 2004; Demsetz, 1968), garantia de direitos residuais (K. Foss \& Foss, 2004, Langlois, 1992), e em situações de elevada especificidade (Crook et al., 2013; Ghozzi, Soregaroli, Boccaletti, \& Suaveé, 2016; Poppo \& Zenger, 1998; Tebboune \& Urquhart, 2016; Williamson, 1985).

Segundo extensa literatura (Barney, 1991; Langlois, 1992; Penrose, 1959; Peteraf, 1992; Wernerfelt, 1984), a VBR foca a identificação dos recursos estratégicos e de suas condições, para aquisição e sustentação de vantagem competitiva. Porém, na visão de autores, como Argyres e Zenger (2012), Combs e Ketchen (1999), Langlois (1992), Saes (2009) e Ghozzi, Soregaroli, Boccaletti e Suaveé (2016), os recursos estratégicos podem, também, influenciar na escolha de estruturas de 
governança (TCT). O próprio Williamson (1985), ao discutir a integração vertical, observa que a explicação pela decisão pela integração vertical pode, além dos custos de transação, envolver propósito estratégico.

Nessa linha, Crook, Combs, Ketchen e Aguinis (2013) argumenta que os ativos estratégicos terão um impacto maior na integração hierárquica do que ativos que sejam somente específicos: "ativos que são específicos e estratégicos (valiosos, raros, difíceis de imitar ou substituir) estão mais fortemente relacionados à hierarquia do que ativos que são apenas específicos" (Crook et al., 2013, p. 64). Dito de outra forma, a integração vertical é mais justificada na presença de ativos específicos e, ao mesmo tempo, estratégicos. Diante disso, apresenta-se a seguinte proposição:

Proposição 1.2: Transações de ativos de elevada especificidade e, ao mesmo tempo, estratégicos, tendem à integração vertical.

Pela VBR, o controle permite que recursos estratégicos sejam conservados dentro da organização, restringindo o acesso de concorrentes (Barney, 1991; Ghozzi et al., 2016; Peteraf, 1993; Teece et al., 1997). Por outro lado, vale notar que autores como Argyres e Zenger (2012), Crook et al., 2013, Huo, Han e Prajogo (2016), Poppo e Zenger (1998), Silverman (1999) e Ghozzi et al. (2016), indicam a possibilidade de explorar recursos estratégicos através de acordos externos. Nessa perspectiva, Augusto, Souza e Cario (2017) indicam que a contratação é possível, desde que os recursos estratégicos envolvidos na negociação apresentem dimensões mensuráveis.

Nessa linha, Silverman (1999) e Tebboune e Urquhart (2016) afirmam que a contratação seria uma alternativa possível, a menos que o conhecimento tecnológico envolvido seja altamente tácito ou facilmente transferível e fracamente protegido, dado que a condição estratégica do recurso estaria em risco de ser eliminada.

Barzel (2005), por sua vez, afirma que um alto nível de especialização pode ser obtido pela integração vertical. Além disso, para o autor, a dificuldade de obtenção e transmissão de informação acerca do ativo transacionado indica a integração vertical como a estrutura mais eficiente. Cabe observar que a transferência de recursos estratégicos por diferentes interfaces da cadeia de valor, sem um controle eficiente, abre oportunidade para a captura de valor. Nesses casos, a integração vertical seria a estrutura mais adequada, considerando que a mensuração e os direitos de propriedade ficam comprometidos. Diante disso, propõe-se:

Proposição 1.3: Transações de recursos estratégicos que apresentam dimensões difíceis de serem mensuradas tendem à integração vertical.

Essas proposições de complementaridade direcionadas a entender como a integração se justifica nos estudos de coordenação vertical serão consideradas no estudo do setor automotivo brasileiro. A proposta apresentada, embora seja genérica o suficiente para a compreensão da escolha pela integração vertical em qualquer atividade produtiva, terá seu foco em montadoras automotivas. Conforme identificado, no setor automotivo, notadamente para as montadoras, movimentos de integração e desintegração são descritos, tornando possível o estudo. Ademais, as proposições teóricas aqui apresentadas contribuem para oferecer predição e compreensão à dinâmica desse setor, em particular, bem como para direcionar estudos em outros setores.

\section{Procedimentos Metodológicos}

A presente investigação é de natureza qualitativa, descritiva e teórico-empírica, com recorte transversal no ano de 2016. Como estratégia de pesquisa, foi utilizado o estudo de casos múltiplos, que envolve mais de um caso ou empresa. Na presente investigação, os casos referem-se às três montadoras de automóveis e comerciais leves existentes no Estado do Paraná (ANFAVEA, 2016), denominadas Montadoras A, B e C. 
Apontado como o terceiro polo automotivo do Brasil, após São Paulo e Rio Grande do Sul, o Paraná possui três montadoras de automóveis e comerciais leves localizadas em São José dos Pinhais, quinta maior área da Região Metropolitana de Curitiba (ANFAVEA, 2016). Vale destacar que as montadoras A e B realizaram um processo de aliança em suas atividades operacionais, visando a reduzir custos de produção, conforme especificaram os entrevistados. Ainda assim, suas decisões operacionais se mantêm autônomas, de acordo com a configuração produtiva e competitiva de cada montadora.

A escolha de mais de uma montadora vem ao encontro do exposto por Yin (2005), de que o estudo de casos múltiplos pode gerar resultados com melhor aceitação, quando comparado aos resultados de um estudo de caso único (Yin, 2005). Nesse sentido, múltiplos casos foram escolhidos na presente investigação, visando a compreender se há uma diferença dos tipos de autopeças que são internalizadas e se há uma lógica diferente na decisão pela integração vertical entre as diferentes montadoras investigadas.

Considerando os três maiores polos automotivos do país (SP, RS e PR) e que a dinâmica de funcionamento das montadoras em si é relevante para entender a integração vertical, uma vez que elas internalizam poucos componentes, foi estabelecido contato, via telefone, inicialmente, com montadoras desses três Estados. A partir desse contato inicial, a escolha dos casos foi baseada na conveniência, considerando que foi escolhido como lócus de pesquisa o Estado cujos contatos mais prontamente atenderam a solicitação de realização de entrevista, de forma a facilitar a coleta de dados.

\section{Métodos de coleta de dados}

Os dados primários dessa investigação foram coletados por meio de entrevistas semiestruturadas com os gerentes de compras, de qualidade e de logística das três montadoras paranaenses. A seleção dos entrevistados se deu porque as áreas em que trabalham são as mais próximas das transações com fornecedores de autopeças, indicando o acesso, por parte deles, a conhecimentos sobre aspectos inerentes às vantagens e às desvantagens da decisão pela desintegração e pela integração vertical.

A partir do momento em que áreas-chave foram definidas, o contato se deu via telefone, seguido por e-mail formal explicando os motivos da pesquisa. Todos os entrevistados aceitaram participar da pesquisa no primeiro contato. No caso de dois dos três gerentes de uma das montadoras, a entrevista não foi marcada de antemão, acontecendo no momento da visita à montadora. Vale notar que, apesar dos gerentes de compra, de qualidade e de logística das Montadoras A e B serem os mesmos devido à aliança realizada, as decisões para cada empresa são diferentes. Os itens que a montadora A integra verticalmente são diferentes dos itens da montadora B. Por esse motivo, as montadoras são tratadas como empresas independentes.

Dois agentes-chave, gerentes de desenvolvimento industrial e de desenvolvimento industrial automotivo, pertencentes à Federação das Indústrias do Estado do Paraná (FIEP), também foram entrevistados. A partir dessas entrevistas, pôde-se colher percepções sobre por que as montadoras optam por internalizar apenas alguns componentes específicos, ao invés de externalizar a sua produção. O perfil desses gerentes é apresentado na Tabela 1. 
Tabela 1

Perfil dos Entrevistados das Montadoras Automotivas Paranaenses e dos Pesquisadores da FIEP

\begin{tabular}{|c|c|c|c|}
\hline Entrevistados/Cargo & Idade & $\begin{array}{l}\text { Tempo na Formação } \\
\text { empresa }\end{array}$ & Local da entrevista/ Cidade \\
\hline
\end{tabular}

\begin{tabular}{|c|c|c|c|}
\hline \multicolumn{4}{|l|}{ Montadora A e B } \\
\hline Gerente de Compras & 42 anos & 8 anos & $\begin{array}{l}\text { Graduação em Administração Montadora A - São José dos } \\
\text { de Empresas e Técnico em Pinhais/PR } \\
\text { Mecânica }\end{array}$ \\
\hline Gerente de Logística & 39 anos & 6 anos & $\begin{array}{ll}\text { Graduação em Administração } & \text { Montadora B - São José dos } \\
\text { de Empresas } & \text { Pinhais/PR }\end{array}$ \\
\hline Gerente de Qualidade & 41 anos & 13 anos & $\begin{array}{ll}\text { Graduação em Engenharia da } & \text { Montadora A - São José dos } \\
\text { Produção } & \text { Pinhais/PR }\end{array}$ \\
\hline \multicolumn{4}{|l|}{ Montadora C } \\
\hline Gerente de Compras & 50 anos & 30 anos & $\begin{array}{l}\text { Graduação em Engenharia Montadora C - São Bernardo } \\
\text { Mecânica e Pós-graduação do Campo/São Paulo } \\
\text { em Administração }\end{array}$ \\
\hline Gerente de Logística & 40 anos & 12 anos & $\begin{array}{l}\text { Graduação em Engenharia Montadora C - São José dos } \\
\text { Mecânica, Técnico em Pinhais-PR } \\
\text { Mecânica e Pós-graduação } \\
\text { em Planejamento e Gestão de } \\
\text { Negócios }\end{array}$ \\
\hline Gerente de Qualidade & 54 anos & 15 anos & $\begin{array}{l}\text { Graduação em Administração Montadora C - São Bernardo } \\
\text { de Empresas e MBA em do Campo/São Paulo } \\
\text { Gestão Empresarial }\end{array}$ \\
\hline \multicolumn{4}{|l|}{ FIEP } \\
\hline $\begin{array}{l}\text { Gerente de } \\
\text { Desenvolvimento } \\
\text { Industrial }\end{array}$ & 40 anos & 6 anos & $\begin{array}{l}\text { Graduação em Ciências } \\
\text { Econômicas, MBA } \text { em } \\
\text { Gestão de Recursos Humanos } \\
\text { e Mestradoriba } \\
\text { Desenvolvimento Econômico em }\end{array}$ \\
\hline $\begin{array}{l}\text { Gerente de } \\
\text { Desenvolvimento } \\
\text { Industrial Automotivo }\end{array}$ & 48 anos & 6 anos & $\begin{array}{l}\text { Graduação em Ciências FIEP/Curitiba } \\
\text { Econômicas e Mestrado em } \\
\text { Desenvolvimento Econômico }\end{array}$ \\
\hline
\end{tabular}

Nota. Fonte: Elaborado pelos autores, a partir das entrevistas.

De forma a se alcançar maior confiabilidade e profundidade nas informações obtidas das montadoras, também foram entrevistados gerentes de logística de sete empresas fornecedoras diretas de autopeças. Foram realizadas 18 entrevistas in loco, com duração média de uma hora cada, sendo que a fala dos entrevistados foi gravada, transcrita e salva em meio eletrônico.

Na seleção dos fornecedores, foram considerados critérios como: (a) ser fornecedor direto da montadora (fornecedores do tier 1), de forma a ratificar, via triangulação, as informaç̧ões obtidas a partir de pessoas com experiência nas transações de autopeças com as montadoras; (b) o tempo de relação, superior a dez anos, visando a se obter maior profundidade nas respostas pela experiência e pelo conhecimento dos entrevistados acerca das ocorrências associadas às decisões das montadoras pela integração vertical; (c) a disponibilidade dos fornecedores em participar da pesquisa.

As empresas fornecedoras foram classificadas em: (a) empresas de alta tecnologia (fornecedores de sistema de injeção, motor de partida, ABS, air bags, ECUs (unidades de comando eletrônica), bomba de combustível (Fornecedor 6), bem como de componentes de motor e suspensão (Fornecedor 7); (b) 
empresas de média tecnologia (módulos de ventilação e refrigeração de motores, de sistema de banco, de motores dos levantadores de vidro (Fornecedor 4) e de sistema de direção (Fornecedor 5); (c) empresas de baixa tecnologia (peças plásticas de interior, como módulos de painel de porta, de colunas, de painel de instrumento, de proteções de caixa de fusível (Fornecedor 2), de painel de frente e bancos (Fornecedor 3), bem como de para-choques, faróis e chicotes (Fornecedor 1). Na Tabela 2, são indicadas informações sobre as empresas fornecedores e sobre os perfis dos entrevistados.

Tabela 2

Empresas Fornecedoras do Setor Automotivo Paranaense e o Perfil dos Entrevistados

\begin{tabular}{|c|c|c|c|c|c|c|}
\hline Empresa & $\begin{array}{l}\text { Principais produtos } \\
\text { fornecidos }\end{array}$ & $\begin{array}{l}\text { Tempo de } \\
\text { relação com a } \\
\text { montadora }\end{array}$ & Cargo & Idade & $\begin{array}{l}\text { Tempo na } \\
\text { empresa }\end{array}$ & $\begin{array}{c}\text { Local da } \\
\text { entrevista - } \\
\text { Cidade/Estado }\end{array}$ \\
\hline EF1 & Módulo de para-choques & 15 anos & $\begin{array}{l}\text { Gerente } \\
\text { Logística }\end{array}$ & 37 & 6 anos & $\begin{array}{l}\text { São José dos } \\
\text { Pinhais/PR }\end{array}$ \\
\hline EF2 & $\begin{array}{l}\text { Peças plásticas de interior } \\
\text { (módulo de painel de porta, de } \\
\text { painel de instrumentos, etc) }\end{array}$ & 30 anos & $\begin{array}{l}\text { Gerente } \\
\text { Logística }\end{array}$ & 45 & 13 anos & $\begin{array}{l}\text { São José dos } \\
\text { Pinhais/PR }\end{array}$ \\
\hline EF3 & $\begin{array}{l}\text { Painel de frente, de porta e } \\
\text { bancos }\end{array}$ & 20 anos & $\begin{array}{l}\text { Gerente } \\
\text { Logística }\end{array}$ & 35 & 8 anos & $\begin{array}{l}\text { São José dos } \\
\text { Pinhais/PR }\end{array}$ \\
\hline EF4 & $\begin{array}{c}\text { Sistema de bancos, módulo de } \\
\text { refrigeração dos motores e de } \\
\text { levantadores de vidro, peças } \\
\text { para o motor }\end{array}$ & 30 anos & $\begin{array}{l}\text { Gerente } \\
\text { Logística }\end{array}$ & 39 & 10 anos & $\begin{array}{l}\text { São José dos } \\
\text { Pinhais/PR }\end{array}$ \\
\hline EF5 & Sistema de direção & 20 anos & $\begin{array}{l}\text { Gerente } \\
\text { Logística }\end{array}$ & 50 & 15 anos & $\begin{array}{l}\text { São José dos } \\
\text { Pinhais/PR }\end{array}$ \\
\hline EF6 & $\begin{array}{l}\text { Sistema de injeção, motor de } \\
\text { partida, ABS, airbags, ECU } \\
\text { (unidade de comando } \\
\text { eletrônica), bomba de } \\
\text { combustível }\end{array}$ & 25 anos & $\begin{array}{l}\text { Gerente } \\
\text { Logística }\end{array}$ & 52 & 22 anos & $\begin{array}{l}\text { Escritório - } \\
\text { Campinas/São } \\
\text { Paulo }\end{array}$ \\
\hline EF7 & $\begin{array}{l}\text { Componentes de motor e } \\
\text { suspensão }\end{array}$ & 30 anos & $\begin{array}{l}\text { Gerente } \\
\text { Logística }\end{array}$ & 49 & 20 anos & $\begin{array}{c}\text { São Bernardo do } \\
\text { Campo/SP }\end{array}$ \\
\hline
\end{tabular}

Nota. Fonte: Elaborado pelos autores a partir das entrevistas.

No roteiro de questões, similar para montadoras e fornecedores, o primeiro conjunto de perguntas, tomando-se como base os pressupostos de Williamson (1985), foi feito visando caracterizar a presença dos atributos de transação (especificidade de ativos, frequência e incerteza) e pressupostos comportamentais (racionalidade limitada e oportunismo) da TCT. Um segundo conjunto de perguntas alinhado à TCM, utilizando-se Barzel $(2002,2005)$, focou a possibilidade de mensuração e garantia dos direitos de propriedade das autopeças.

Um terceiro conjunto de perguntas, orientado, principalmente, pelas proposições de Barney (1991) e Peteraf (1993), foi feito com o objetivo de caracterizar a presença de recursos considerados estratégicos (VBR). Em um segundo momento, buscou-se identificar o que a empresa produz internamente e entender o motivo dessa escolha. Todas as entrevistas foram feitas presencialmente $\mathrm{e}$ várias visitas foram necessárias, bem como trocas de e-mails e mensagens, a fim de completar as informações obtidas. 


\section{Procedimentos para estruturação e análise das informações obtidas}

Neste estudo, a perspectiva de complementaridade foi construída sob a orientação de Ennen e Richter (2010), que indicam a utilização dessa perspectiva nos casos em que: "O valor econômico total adicionado pela combinação de dois ou mais fatores complementares em um sistema de produção ultrapassa o valor que seria gerado pela aplicação desses fatores de produção em isolamento" (p. 208). Isso implica avaliar que a soma dos pressupostos de cada teoria individualmente (ativos específicos, mensuráveis e estratégicos) é diferente da soma de suas relações na escolha pela integração vertical.

Simultaneamente, foram consideradas as colocações de Bacharach (1989) e Suddaby (2010) sobre como construir clareza no desenvolvimento de teorias de gestão. Bacharach (1989, p. 498) define uma teoria como "um sistema de construtos ... relacionados uns com os outros por meio de proposições". Na mesma linha, Sudabby (2010) reafirma que, na construção de um modelo teórico, deve haver relação semântica dos construtos entre si. Na presente proposta, os construtos e suas relações são evidenciados na Tabela 3.

Tabela 3

\section{Proposições e Subproposições sobre a Complementaridade da TCT, da TCM e da VBR}

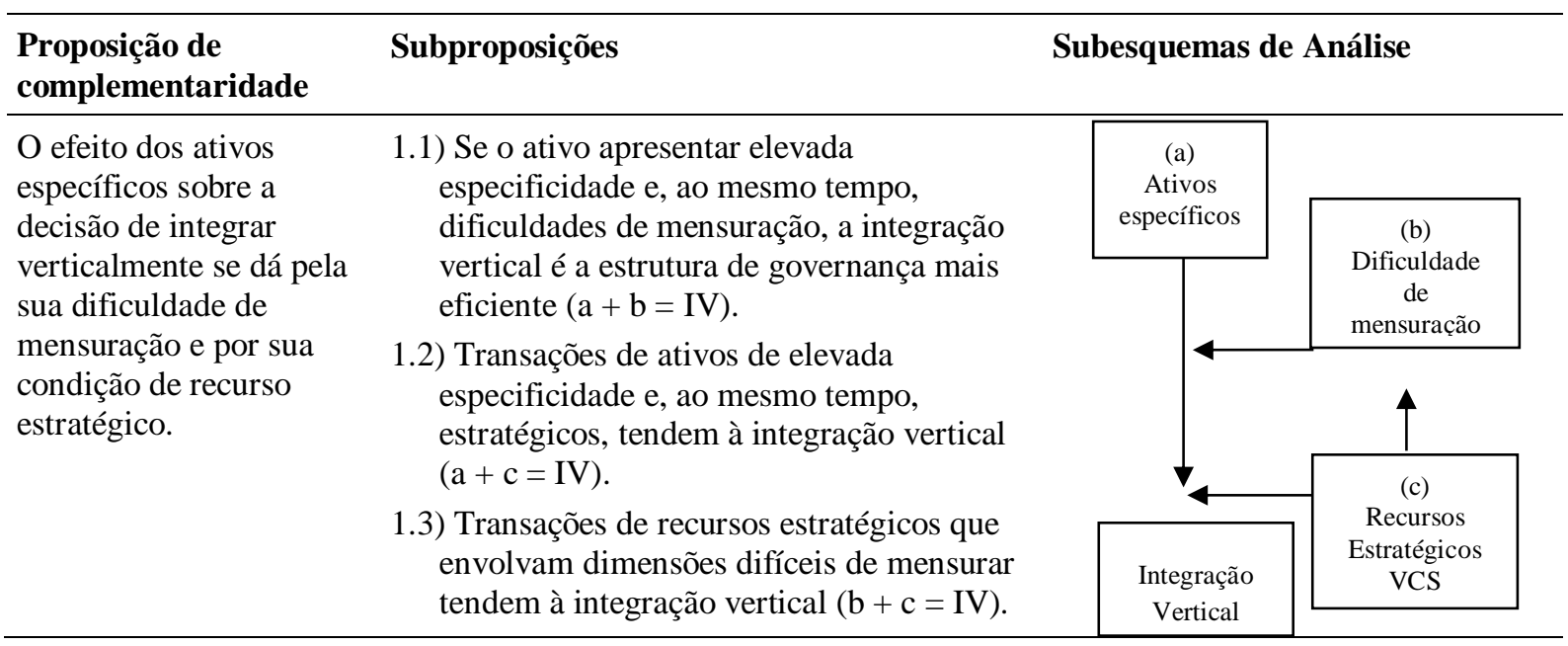

Nota. Fonte: Elaborado pelos autores a partir das entrevistas.

Destaca-se, ainda, que a formulação das proposições apresentadas considerou o proposto por $\mathrm{N}$. J. Foss e Hallberg (2017) de que "o progresso teórico pode resultar também de mudanças nas proposições de uma teoria como um resultado do debate acadêmico, independente de qualquer teste empírico". Vale salientar, nesse sentido, que a formulação das proposições apresentadas foi fruto de vários debates em grupos de pesquisa e com pesquisadores, nacionais e internacionais, da área da NEI. Por fim, buscou-se atender as indicações de Reay (2014) quanto ao desenho de pesquisas qualitativas, ou seja, atentou-se para a qualidade nos dados obtidos, ao uso de literatura relevante, com os clássicos de cada teoria, e à descrição detalhada dos procedimentos.

\section{Método de análise de dados}

Para analisar os dados obtidos na presente investigação, foi utilizado o método de análise de conteúdo, com apoio do software Atlas Ti. Bardin (2004) assinala três etapas básicas desse método, que foram adaptadas na presente investigação: pré-análise, descrição analítica e interpretação inferencial. Na pré-análise, em que se realiza a organização do material obtido (Bardin, 2004), as entrevistas foram transcritas, lidas e as falas foram alocadas dentro de cada proposição, que recebeu um tópico correspondente. 
$\mathrm{Na}$ fase de descrição analítica, o material é submetido a um estudo aprofundado, orientado pelas hipóteses e pelo referencial teórico, sendo a codificação um importante processo a ser efetuado nesse momento (Bardin, 2004). Segundo Dieh e Tatim (2004), a codificação, na pesquisa qualitativa, consiste na atribuição de um nome conceitual às categorias, o qual deve relacionar-se ao que os dados representam no contexto da pesquisa.

Assim, com suporte do software Atlas Ti, os dados primários, advindos das entrevistas transcritas, foram selecionados e agrupados em quatro categorias-chave: (a) integração vertical; (b) ativos específicos; (c) ativos mensuráveis; (c) recursos estratégicos. Além da integração vertical, que é o temachave, foco deste estudo, a escolha de cada categoria se deu a partir de cada abordagem teórica apresentada: ativos específicos para a TCT, ativos mensuráveis para TCM e recursos estratégicos para VBR. A interação das três últimas categorias é apresentada, na Tabela 3, como influenciadora da escolha da integração vertical.

A terceira fase, identificada por Bardin (2004), é a da interpretação inferencial, em que se busca alcançar maior intensidade da análise e o pesquisador pode fazer inferências e realizar interpretações relacionadas aos objetivos previstos. Seguindo esses indicativos, a análise de dados foi realizada, em que se buscou interpretar o sentido de cada fala dos entrevistados, frente às categorias elencadas e às proposições estabelecidas, bem como realizar as conclusões do trabalho.

\section{Análise dos Resultados: Complementaridade entre Custos de Transação, de Mensuração e Recursos Estratégicos}

A partir do objetivo estabelecido nesse estudo, buscou-se, nessa seção, desenvolver a análise teórico-empírica das proposições relacionadas à complementaridade da TCT, TCM e VBR na escolha pela integração vertical. Para tanto, tomaram-se como referência as entrevistas realizadas com gerentes das montadoras, de empresas fornecedoras diretas de autopeças e com coordenadores da FIEP.

\section{Complementaridade: ativos específicos e difíceis de mensurar}

Identificou-se que as montadoras investigadas internalizam, no âmbito do produto, o motor, a estamparia e a pintura, sendo que a Montadora $\mathrm{C}$ ainda produz o câmbio. No âmbito do processo, as montadoras são responsáveis pelo desenvolvimento do projeto de cada carro, principalmente o design e a montagem. Ao serem questionados sobre o motivo da decisão de internalizar esses componentes e processos, os entrevistados indicaram como principal argumento a necessidade de controle.

Identificou-se que esse controle é motivado a partir de duas preocupações principais: a) custos, envolvendo noções de especificidade e mensuração (eficiência), bem como os custos produtivos; $b$ ) aspectos estratégicos, envolvendo core competence, qualidade superior das montadoras na fabricação de autopeças e sua proteção estratégica.

Os custos envolvendo a noção de especificidade de ativos, na linha estabelecida por Williamson (1985, 1996), são considerados por todos os entrevistados. Contudo, constatou-se que essa noção é sempre aliada a algum outro fator, além da perda de valor da autopeça quando empregada em uma segunda alternativa, como definido pelo autor. Apesar da presença de investimentos especializados e possibilidade de comportamento oportunista, conforme proposto por Klein et al. (1978), Williamson (1985) e Crook et al. (2013), a busca pela internalização, conforme os entrevistados, não se justifica apenas por essas condições. Durante a entrevista, o Gerente de Qualidade da Montadora C exemplifica claramente essa constatação: 
"tudo o que a gente faz é específico para um determinado carro. O painel de porta do carro x é diferente da do carro y .... Você me pergunta: É por isso que vocês fazem internamente? Eu respondo: Não, porque se fosse assim eu faria tudo internamente, porque tudo é específico para cada carro .... A montadora tem que ter outra motivação para fazer internamente, tem que ser difícil de transportar, tem que ser estratégico, ou ter algum risco, técnico mesmo, de comprar fora, do fornecedor não fazer direito, não ter qualidade, ou não entregar, sempre vai ter algo a mais, entende?"

Diante dessa constatação, percebe-se que, apesar de fator influenciador, apenas a especificidade de ativos não justifica a integração vertical como melhor escolha, embora Williamson (1985) indique ser esse o atributo mais importante. Percebeu-se, a partir dos relatos dos entrevistados, que a preocupação não está somente no alto nível de especificidade transacionado entre fornecedores de autopeças e montadoras, e a inerente possibilidade de comportamento oportunista presente. A integração vertical é escolhida como opção adequada de governança motivada, também, na consideração de outros fatores.

Em meio a esses fatores, aspectos de mensuração da autopeça, seguindo a concepção de Barzel (1997, 2002, 2005), foram evidenciados. Quando a autopeça apresenta alta especificidade e a montadora tem dificuldades de realizar o controle do fornecedor, do desenvolvimento do projeto, da fabricação e da entrega da autopeça, ela busca integrar: "Cada autopeça tem uma especificação de qualidade que precisa ser rigorosamente cumprida, tamanho, cor, medidas, volume, tudo. Se começa a dar problema, nós começamos a pensar em fazer por nós mesmos", afirma o gerente de Qualidade da Montadora C. Ademais, para os entrevistados, algumas autopeças necessitam ter controle total da montadora porque a dificuldade de mensuração pode expor sua reputação e capacidade de verificar a qualidade do produto final:

\footnotetext{
"Tem coisa que você precisa ter controle técnico, porque um problema naquilo acaba com a reputação da empresa. O motor, por exemplo, é feito especificamente para o nosso carro, mas não dá para você controlar tudo que o fornecedor vai usar lá dentro, aqui a gente consegue; lá, vai saber se ele coloca algo mais barato num lote, a gente vai ficar sabendo só depois que o negócio explodir no mercado.... o recall queima muito .... Não dá.... Então, a gente faz também porque é difícil de controlar lá fora.” (Gerente de Qualidade da Montadora A)
}

Os dados empíricos, portanto, indicam convergência com proposição 1.1 , de que se o ativo apresentar elevada especificidade e, ao mesmo tempo, dificuldade de mensuração, a integração vertical pode ser a estrutura de governança mais eficiente. Dito de outra forma, a presença de ativos específicos (TCT), complementada pelas dificuldades de mensuração (TCM), pode gerar custos de transação para as montadoras na sua coordenação externa, estimulando a produção própria ou internalizada pela integração vertical.

Nesse caso, pode-se observar que a especificidade de ativos físicos (motor, estamparia, pintura, câmbio e design) e, consequentemente, dedicados (estrutura de montagem de carros de cada montadora) está presente nas transações de forma acentuada, justificando a integração vertical, nos termos propostos por Williamson $(1985,1996)$. A necessidade de informação antes, durante e após a montagem do veículo, definindo condições de garantia e rastreabilidade, ou seja, condições efetivas de transferência de informação, notadamente em situações envolvendo recall, também indica a integração vertical como a forma de organização mais adequada, ratificando o racional de Barzel (2005).

Dessa forma, confirmou-se que o controle, por meio da integração vertical, além de ser motivado pela presença de investimentos específicos (Tebboune \& Urquhart, 2016; Williamson, 1985, 1991; Zylbersztajn, 2009), também é utilizado para o garantir direitos de propriedade das montadoras sobre as dimensões das autopeças utilizadas (Barzel, 2002, 2005).

\section{Complementaridade: ativos específicos e recursos estratégicos}

No aspecto estratégico, percebeu-se que a motivação para internalizar alguns itens envolvidos na produção de carros ocorre devido à necessidade das montadoras em focar no seu core competence. Os entrevistados destacaram que, décadas atrás, as montadoras internalizavam grande parte de sua 
produção. Mais recentemente, essas montadoras passaram por um processo de outsourcing, enxugando sua estrutura interna ao externalizar grande parte das peças cuja produção era de sua responsabilidade. Uma mudança radical na quantidade de empregados e na estrutura de produção foi observada a partir de então.

Essa reestruturação ocorreu, segundo os entrevistados, devido ao fato de que o foco de qualquer montadora deveria ser montar o veículo e não produzir autopeças. Essa nova orientação é confirmada pelo Gerente de Compras da Montadora C: "Há 50 anos se fazia tudo, se derretia até o ferro. Agora o foco é montar. Da mesma forma que os fornecedores são especialistas nas autopeças que eles fornecem para nós, nós somos especialistas em montar carros. Cada um foca no seu principal propósito, e consegue excelência no que faz".

Além de focar no processo de montagem, as montadoras internalizam a produção do motor, design, estamparia, pintura e câmbio. O Gerente de Qualidade da Montadora B afirma: "Normalmente você não terceiriza aquilo que é o seu segredo, o diferencial que você põe no mercado, que é a identidade da marca, como o motor que tem essa de ser o coração do carro, e tem alguns segredos de montagem". As colocações dos entrevistados remetem ao pressuposto de core competence, ou competência essencial, apresentada por Prahalad e Hamel (1990). Isso porque, tanto o processo de design e montagem como a produção do motor, a pintura, a estamparia e o câmbio constituem o conjunto de habilidades ou tecnologias sob os quais as montadoras constroem seus diferenciais.

Paralelamente à abordagem de core competence, a qualidade superior é outro ponto relacionado ao aspecto estratégico destacado pelos entrevistados, que pode motivar a internalização. A busca interna de recursos e capacidades para garantir a qualidade superior é evidenciada principalmente para autopeças visíveis pelos clientes, em pontos nos quais as necessidades mais se apresentam. Essa indicação corrobora o exposto por Sörensen (2006) sobre a importância do desenvolvimento de recursos e capacidades internas, em montadoras automotivas, para satisfazer os clientes. O Gerente de Qualidade da Montadora $\mathrm{C}$ resume a posição dos entrevistados: "Tem a questão de que nós fazemos melhor também. O carro tem 2 partes: a visível e a não visível. O que é visível a gente faz, como a estamparia. O que o cliente não vê, não tem necessidade de qualidade visual, mas de qualidade estrutural e funcional, aí nós compramos".

A proteção de um diferencial estratégico também foi relacionada à integração vertical pelos gerentes entrevistados. Na visão deles, a montadora pode optar pela integração visando controlar o que é altamente estratégico e constitui a identidade do seu veículo, como é o caso do motor, design, estamparia, câmbio e pintura. Esse consenso se resume na fala do Gerente de Logística da Empresa Fornecedora 2: "o design cada montadora tem o seu. E tem cliente que escolhe por isso. Porque essa parte de design e de estamparia forma a parte visual do carro, e impacta muito na hora de comprar. É uma tecnologia deles, de controle deles".

A constante evolução tecnológica, que a montadora mantém na fabricação desses itens, também reforça a sua proteção como diferenciais estratégicos. Essa afirmação é exemplificada pelo Gerente de Logística da Empresa Fornecedora 2: "O motor é um produto que vai no carro que a montadora fabrica, ela ganha fazendo porque é pra ela, ela consegue excelência .... Então, além desse foco dela de montar carro, tem essa questão de proteger seu diferencial e deixar isso sob seu controle".

Diante das colocações dos entrevistados, é possível respaldar a proposição 1.2, de que transações de ativos de elevada especificidade e, ao mesmo tempo, estratégicos, que tendem à integração vertical. Assim, a questão estratégica (VBR) se associa à questão dos custos de transação (TCT) na decisão das montadoras pela integração vertical. Nesse raciocínio, confirma-se o exposto por Crook et al. (2013) que destacam que ativos que são específicos e estratégicos estão mais fortemente relacionados à integração vertical do que ativos apenas específicos.

Constatou-se, a partir das entrevistas, que os fatores motivadores da integração vertical nas montadoras (foco no core competence; qualidade superior na produção de algumas peças; necessidade de proteger seus diferenciais) são percepções desenvolvidas ao longo do seu path dependence, seguindo 
a mesma linha apresentada em Teece, Pisano e Shuen (1997). Essas percepções guiam as decisões de investimento relacionadas, notadamente, ao desenvolvimento de inovações tecnológicas que reforçam a integração, conforme exposto por Liu (2016).

A qualidade superior na fabricação de algumas autopeças e a necessidade de proteger diferenciais corrobora, também, a colocação de K. Foss \& Foss (2005) acerca da geração de valor. Ao integrar verticalmente, a montadora consegue gerar valor e, ao mesmo tempo, garantir que o valor gerado não seja apropriado pela concorrência. Assim, a integração vertical, enquanto estrutura de governança nas montadoras automotivas, resolve o problema de apropriação de valor, apontado por K. Foss \& Foss (2005), em autopeças estratégicas e de elevada especificidade.

A integração vertical para alavancar as habilidades internamente, ainda encontra respaldo nas pesquisas de Argyres e Zenger (2012), Crook et al. (2013), Demsetz (1968), K. Foss e Foss (2004), Ghoshal e Moran (1996), Jacobides e Winter (2005), Langlois (1992), Poppo e Zenger (1998), Saes (2009), Tebboune e Urquhart, 2016, Ghozzi et al. (2016) e Williamson (1999). Nesse caso, o domínio de habilidades é focado na produção de autopeças consideradas diferenciais para as montadoras.

Da mesma forma, a escolha pela integração vertical visando proteger diferenciais estratégicos, como motor, design, estamparia e pintura, ratifica as afirmações de Argyres e Zenger (2012), Combs e Ketchen (1999), Langlois (1992), Williamson (1999), Saes (2009) e Ghozzi et al. (2016). Ou seja, a identificação desses recursos pelas montadoras é complementada pela utilização da estrutura integrada verticalmente, que serve como seu mecanismo de gestão e proteção na construção de vantagens competitivas. Esses diferenciais são identificados como capazes de gerar vantagem competitiva, configurando-se como raros e valiosos, necessitando de proteção pela integração vertical, conforme o pensamento de Barney (1991).

\section{Complementaridade: recursos estratégicos e difíceis de mensurar}

Recursos considerados estratégicos pelas montadoras, em nível de produto, como o motor (coração do carro) e a estamparia (design externo que influencia a decisão do cliente), são considerados difíceis de medir ou mesmo imensuráveis pelos entrevistados. O Gerente de Logística da Montadora A explica: "Dá para mensurar o que tem dentro, mas é difícil porque o motor vai chegar aqui fechado, eu não vou abrir pra conferir cada motor, aí teria que colocar gente lá para controlar, mas como é um produto especial, nós fazemos aqui”.

Além da dificuldade de medir, o Gerente de Compras da Montadora $\mathrm{C}$ destaca a imensurabilidade (TCM) de alguns recursos de importância estratégica (VBR): "Tem coisa que é imensurável porque é muito importante, não tem como medir o impacto do design, é um conceito subjetivo de alta importância estratégica, porque é um chamariz do veículo. Então você faz, porque precisar dominar esse conceito".

Diante dos dados primários, observou-se, nas empresas estudadas, que a decisão pela internalização de recursos, como motor e design, é tomada pela sua dificuldade, ou, até mesmo, pela impossibilidade de mensuração, bem como pela falta de informação que poderia indicar captura de valor, seguindo o que propõe Barzel $(2002,2005)$. No entanto, essa decisão também é potencializada pela condição estratégica dessas autopeças, o que pode ser constatado na fala do Coordenador de Desenvolvimento Industrial Automotivo da FIEP:

\footnotetext{
"Motor tem que ter tecnologia. Hoje tem montadora que desenvolve motor para a Fórmula 1. Então ela tem uma alta equipe de engenharia que trabalha com isso. Tem tecnologias de motor de Fórmula 1 que são repassadas para o veículo, e isso constantemente acontece. Nesse caso, nós temos tecnologias para tornar o motor mais forte, mais econômico; nós desenvolvemos isso. É um investimento estratégico. Tem custo? Tem, mas tem um diferencial que está sendo desenvolvido. Você tem também um equilíbrio entre estratégia e custo. Tem coisa custosa, mas que precisa ser desenvolvida pela montadora."
}

Essa intenção de controlar o desenvolvimento de recursos vistos como estratégicos e protegê-los do acesso dos concorrentes encontra respaldo em Barney (1991), Peteraf (1993), Teece et al. (1997) e Ghozzi et al. (2016). Diante desses dados primários, é possível encontrar embasamento para a 
confirmação da proposição 1.3, de que transações de recursos estratégicos que apresentam dimensões difíceis de mensurar tendem à integração vertical.

Observou-se que, na trajetória das montadoras investigadas, diversos recursos geradores de vantagem competitiva, que hoje são comuns entre os concorrentes, apresentaram-se como inovações, tais como o bluetooth, o GPS integrado no veículo, com cartão SD, o sensor de ré, air bags, entre outros. Nesses casos, mesmo sendo considerados recursos valiosos e raros para as montadoras, geradores de vantagens competitivas, nos termos de Barney (1991), quando foram lançados, muitos deles foram desenvolvidos conjuntamente com os fornecedores.

Essa situação corrobora o exposto por diversos autores sobre a possibilidade de transacionar recursos estratégicos em acordos externos (Argyres \& Zenger, 2012; Augusto, Souza, \& Cario, 2017; Crook et al., 2013; Huo, Han, \& Prajogo, 2016; Poppo \& Zenger, 1998; Silverman, 1999; Ghozzi et al., 2016). Ainda assim, os entrevistados são unânimes ao afirmar que, nos contratos em que não conseguem obter mecanismos de mensuração para garantir seus direitos de propriedade de autopeças, estratégicas ou não, a integração vertical é buscada.

Essa constatação é visualizada na fala do Gerente de Logística da Montadora C: "A contratação ocorre muito hoje em dia no setor, pra tudo, conforme eu falei, mas ela só ocorre porque funciona, a gente consegue fiscalizar tudo o que o fornecedor usa ... quanto mais problema dá, mas a montadora vai querer dominar o processo". Tal constatação também ratifica a proposição de que recursos estratégicos difíceis de mensurar tendem à integração, e encontram, também, respaldo, ao serem discutido por Monteverde e Teece (1982), Silverman (1999) e Tebboune e Urquhart (2016) e Augusto et al. (2017). Isso porque, esses autores apontam a necessidade de internalizar a produção nas situações em que o conhecimento tecnológico envolvido é facilmente transferível e fracamente protegido.

\section{Conclusões}

O objetivo na presente investigação foi compreender como se dá a integração vertical, considerando a complementaridade dos custos de transação (TCT), de mensuração (TCM) e dos recursos estratégicos (VBR) em montadoras automotivas localizadas no Estado do Paraná. Para tanto, pressupôsse que o efeito dos ativos específicos sobre a decisão das empresas integrarem verticalmente se justifica pela sua dificuldade de mensuração e sua condição de recurso estratégico.

Em geral, no estudo, observou-se que a escolha pela integração vertical, caracterizada pela internalização da produção do motor, estamparia, pintura, design e câmbio, é motivada pela necessidade de controle, envolvendo duas orientações: custos e aspectos estratégicos. Para desenvolver um motor e dominar sua produção, a montadora aumenta seus custos de produção, mas, paralelamente, aumenta o potencial de obter ganhos estratégicos e diminui seus custos de transação, associados a perdas por oportunismo e apropriação de renda.

Notou-se que, nos casos em estudo, paralelamente à condição de especificidade das autopeças, o foco em aspectos estratégicos, como o core competence e a capacidade superior das montadoras na fabricação de determinadas autopeças, bem como a necessidade de sua proteção estratégica, evidenciaram-se como motivadores da integração vertical (sub proposição 1.1). Em complemento, dada a dificuldade de mensuração para garantia de propriedade nas dimensões dos ativos específicos envolvidos (design, estamparia, motor e câmbio), a integração vertical é justificada, corroborando a segunda sub proposição (1.2). Por fim, a constatação de que esses recursos estratégicos apresentam difícil mensuração (partes internas de motor e design, por exemplo) e, por isso, motivam a integração vertical, o que confirma a subproposição (1.3).

Assim, a proposição geral foi corroborada, já que os itens citados pelos entrevistados (design, estamparia, motor e câmbio) não têm a sua produção internalizada somente por serem específicos. 
Aspectos de mensuração e sua condição estratégica foram apontados como motivadores complementares na decisão pela integração vertical.

Teoricamente, a contribuição deste estudo é oferecer uma visão de como teorias múltiplas podem ajudar a entender melhor as opções de fronteira, particularmente no contexto do setor automotivo, o que não impede sua replicação em outros setores. Particularmente, mostrou-se que as explicações da escolha pela integração vertical têm maior amplitude ao se considerar conjuntamente os pressupostos das TCT, TCM e VBR. Nesse caso, as presenças de recursos estratégicos, de elevada especificidade e, principalmente, de difícil mensuração, orientam para uma estrutura integrada verticalmente.

De forma pontual, destaca-se a importância decisiva da mensuração, ainda pouco discutida, no tratamento de aspectos associados ao tamanho das organizações, notadamente em seu processo de crescimento vertical. A necessidade de internalização da produção de ativos de elevada especificidade e estratégicos só se justifica diante da dificuldade de obter informações sobre suas características mensuráveis.

Em termos práticos, a presente pesquisa contribui ao oferecer aos gerentes, envolvidos em tais decisões, múltiplas unidades de análise para ajudá-los a tomar melhores decisões. Ademais proposições apresentadas e confirmadas podem ser usadas por empresas à montante para avaliar decisões à jusante sobre estruturas de governanças, levando em consideração não apenas os custos de produção, mas também os custos de transação associados a ativos de elevada especificidade e sua condição estratégica. O direcionamento desses achados oferece contribuição efetiva na explicação do crescimento vertical, via internalização da produção, em estudos sobre as firmas em cadeias produtivas.

Entre as limitações desta pesquisa, destaca-se que novas perspectivas poderiam ser alcançadas para outros tipos de padrões de cadeias e redes de fornecimento. Assim, embora os três casos utilizados sejam representativos, o acréscimo de novas organizações poderia ampliar a lente teórica e agregar novas nuances aos resultados. Ademais, como já indicado por Cunha, Saes e Mainville (2015) como limitação comum aos estudos que abordam custos de transação, mecanismos de mensuração de valor de recursos ou ativos, bem como de definição quantitativa de custos de transação e mensuração, não foram implementados.

Diante disso, propõem-se como sugestões de futuros estudos a reaplicação dessa proposta de complementaridade no mesmo ou em outros setores. Como já apontaram Durand, Grant e Madsen (2017), um dos caminhos para combater a fragmentação da área da estratégia, e propiciar o seu amadurecimento, é identificar e promover desenvolvimentos teóricos e análises empíricas que integram vários fluxos teóricos. Isso pode ser feito, segundo os autores, conciliando diferentes teorias e resultados que abordam o mesmo fenômeno, mas com diferentes previsões e resultados.

A realização de pesquisas quantitativas, visando explicar relações de causa-efeito envolvendo a integração vertical, bem como visões mais dinâmicas a partir de estudos longitudinais, mostram-se igualmente promissoras. Além disso, discutir a contribuição de recursos estratégicos para a realização de inovações, como indicado por Sanches e Machado (2014), ou, até mesmo, o papel da inovação sobre a escolha da integração vertical, como sugerido por Liu (2016), complementando com a influência dos custos de transação nesse processo, pode trazer novas percepções sobre estruturas de governança no setor automotivo.

Por fim, como já sugerido no trabalho de Cunha et al. (2015), é válido buscar compreender como o ambiente institucional pode alterar as influências sobre a complexidade que envolve a escolha das estruturas de governança utilizadas. O objetivo, em última instância, é que novas questões surjam e, com elas, novos desafios para pesquisadores que busquem avançar nas discussões sobre os fatores influenciadores das fronteiras organizacionais, cujas lacunas ainda se evidenciam na literatura existente. 


\section{Nota}

${ }^{1}$ A pesquisa foi financiada pela CAPES (Processo: BEX 11163/13-5).

\section{Contribuições}

$1^{\circ}$ autor: estruturação e redação do artigo, desde a introdução, referencial teórico, coleta e análise de dados, conclusões, referências e revisões finais.

$2^{\circ}$ autor: orientações e discussões sobre o artigo, correções do texto, redação de várias partes do texto, revisões finais.

$3^{\circ}$ autor: correções e revisão final do texto.

\section{Referências}

Argyres, N., \& Zenger, T. (2012). Capabilities, transaction costs, and firm boundaries. Organization Science, 23(6), 1643-1657. http://doi.org/10.2307/23362018

Associação Nacional dos Fabricantes de Veículos Automotivos. (2016). Anuário da indústria automotiva brasileira 2016. Recuperado em 20 de janeiro, 2016, de http://www.virapagina.com.br/anfavea2016/index.html\#

Augusto, C. A., Souza, J. P., \& Cario, S. A. F. (2017). Strategic contractual relationships in the automotive sector. Revista de Administração, 52(4), 443-455. http://doi.org/10.1016/j.rausp.2017.08.006

Bacharach, S. B. (1989). Organizational theories: Some criteria for evaluation. Academy of Management Review, 14(4), 496 -515. http://doi.org/10.2307/258555

Bardin, L. (2004). Análise de conteúdo. Lisboa: Edições 70.

Barney, J. (1991). Firm resources and sustained competitive advantage. Journal of Management, 17(1), 99-120. https://doi.org/10.1177/014920639101700108

Barney, J., \& Hesterly, W. (2004). Economia das organizações: entendendo a relação entre as organizações e a análise econômica. In S. R. Clegg, C. Hardy, \& W. R. Nord (Orgs.), Handbook de estudos organizacionais: Ações e análise organizacional (3rd ed., pp. 131-179). São Paulo, SP: Atlas.

Barzel, Y. (1997). Economic analysis of property righ (2nd ed). Cambridge: Cambridge University Press.

Barzel, Y. (2002). Organization firms and measurement costs. Congresso da International Society for the New Institutional Economics. Berkeley, California.

Barzel, Y. (2003). Property rights in the firm. In T. L. Anderson \& F. S. Mcchesney (Eds.), Property rights: Cooperation, conflict and law (pp. 43-57). New Jersey: Princeton University Press.

Barzel, Y. (2005). Organizational forms and measurement costs. Journal of Institutional and Theoretical Economics, 161(3), 357-373. https://doi.org/10.1628/093245605774259291 
Coase, R. H. (1937). The nature of the firm. Economica, 4(16), 386-405. https://doi.org/10.1111/j.14680335.1937.tb00002.x

Combs, J. G., \& Ketchen, D. J. (1999). Explaining interfirm cooperation and performance: toward a reconciliation of prediction from the resource-based-view and organizational economics. Strategic Management Journal, 20(9), 867-888. http://www.jstor.org/stable/3094210

Costa, R. M., \& Henkin, H. (2016). Estratégias competitivas e desempenho da indústria automobilística no Brasil. Economia e Sociedade, 25(57), 457-487. http://doi.org/10.1590/19823533.2016v25n2art7

Crook, T. R., Combs, J. G., Ketchen, D. J., \& Aguinis, H. (2013). Organizing around transaction costs: What have we learned and where do we go from here? Academy of Management Perspectives, 27(1), 63-79. http://doi.org/10.5465/amp.2012.0008

Cunha, C. F., Saes, M. S. M., \& Mainville, D. Y. (2015). Custos de transação e mensuração na escolha da estrutura de governança entre supermercados e produtores agrícolas convencionais e orgânicos no Brasil e nos EUA. Gestão e Produção, 22(1), 67-81. http://dx.doi.org/10.1590/0104-530X04612

Demsetz, H. (1968). The cost of transacting. The Quarterly Journal of Economics, 82(1), 33-53. https://doi.org/10.2307/1882244

Dieh, A. A., \& Tatim, D. C. (2004). Pesquisa em ciências sociais aplicadas. São Paulo: Prentice Hall.

Durand, R., Grant, R. M., \& Madsen, T. L. (2017). The expanding domain of strategic management research and the quest for Integration. Strategic Management Journal, 38(1), 4-16. https://doi.org/10.1002/smj.2607

Ennen, E., \& Richter, A. (2010). Literature on complementarities in organizations: The whole is more than the sum of its parts- or is it? A review of the empirical. Journal of Management, 36(1), 207233. https://doi.org/10.1177/0149206309350083

Ferreira, M. P., \& Serra, F. A. R. (2010). Make or buy in a mature industry? Models of client supplier relationships under TCE and RBV perspectives. Brazilian Administration Review, 7(1), 22-39. Retrieved from http://www.scielo.br/pdf/bar/v7n1/v7n1a03.pdf. http://doi.org/10.1590/S180776922010000100003

Foss, K., \& Foss, N. J. (2004). The next step in the evolution of the VBR: Integration with transaction cost economics. Management Revue, 15(1), 107-121. http://openarchive.cbs.dk/bitstream/handle/10398/7303/ckg-wp202004-04.pdf?sequence=1

Foss, K., \& Foss, N. J. (2005). Resources and transaction costs: How property rights economics furthers the resource-based view. Strategic Management Journal, 26(1), 541-555. https://doi.org/10.1002/smj.465

Foss, N. J., \& Hallberg, N. L. (2017). Changing assumptions and progressive change in theories of strategic organization. Strategic Organization, 15(3), 410-422. https://doi.org/10.1177/1476127016671099

Ghoshal, S., \& Moran, P. (1996). Bad for practice: A critique of the transaction cost theory. Academy of Management Review, 21(1), 13-47. https://doi.org/10.5465/AMR.1996.9602161563

Ghozzi, H., Soregaroli, C., Boccaletti, S., \& Sauvée, L. (2016). Impacts of non-GMO standards on poultry supply chain governance: transaction cost approach vs resource based view. Supply Chain Management: An International Journal, 21(6), 743-758. https://doi.org/10.1108/SCM-03-20160089 
Huo, B., Han, Z., \& Prajogo, D. (2016). Antecedents and aconsequences of supply chain information integration: A resource-based view". Supply Chain Management: A International Journal, 21(6), 661-677. https://doi.org/10.1108/SCM-08-2015-0336

Jacobides, M. G., \& Winter, S. G. (2005). Co-evolution of capabilities and transaction costs: Explaining the institutional structure of production. Strategic Management Journal, 26(1), 395-413. https://doi.org/10.1002/smj.460

Klein, B., Crawford, R. G., \& Alchian, A. A. (1978). vertical integration, appropriable rents, and the competitive contracting process. Journal of Law and Economics, 21(2), 297-326. http://doi.org/10.1086/466922

Langlois, R. N. (1992). Transaction-cost economics in real time. Oxford Journal - Industrial and Corporate Change, 1(1), 99-127. https://doi.org/10.1093/icc/1.1.99

Liu, X. (2016). Vertical integration and innovation. International Journal of Industrial Organization, $\begin{array}{lcc}47(1) & 88-120 . & \text { Retrieved } \\ \text { http://www.sciencedirect.com/science/article/pii/S0167718716300029. }\end{array}$ https://doi.org/10.1016/j.ijindorg.2016.02.002

Lung, Y., \& Volpato, G. (2002). Editorial: redesigning the automakers-suppliers relationships in the automotive industry. International Journal of Automotive Technology and Management, 2(1), 39. Retrieved from http://www.inderscience.com/editorials/f128756113941210.pdf

Ménard, C. M., \& Shirlei, M. M. (2014). The future of new institutional economics: From early intuitions to a new paradigm. Journal of Institutional Economics, 10(4), 541-565. https://doi.org/10.1017/S174413741400006X

Monteverde, K., \& Teece D. J. (1982). Supplier switching costs and vertical integration in the automobile industry. The Bell Journal of Economics, 13(1), 206-213. http://doi.org/10.2307/3003441

Neves, L. W. A., Hamachera, S., \& Scavarda, L. F. (2014). Outsourcing from the perspectives of TCE and RBV: A multiple case study. Production, 24(3), 687-699. http://doi.org/10.1590/S010365132013005000082

Penrose, E. T. (1959). The theory of the growth of the firm. New York: John Wiley.

Peteraf, M. A. (1993). The cornerstones of competitive advantage: A resource based view. Strategic Management Journal, 14(1), 179-191. http://doi.org/10.1002/smj.4250140303

Poppo, L., \& Zenger, T. (1998). Testing alternative theories of the firm: Transaction cost, knowledgebased, and measurement explanations for make-or-buy decisions in information services. Strategic Management Journal, 19(9), 853-877. http://doi.org/10.1002/(SICI)10970266(199809)19:9<853::AID-SMJ977>3.0.CO;2-B

Porter, M. (1981). The contributions of industrial organization to strategic management. Academy of Management Review, 6(4), 609-620. http://doi.org/10.5465/AMR.1981.4285706

Prahalad, C. K., \& Hamel, G. (1990). The core competence of the corporation. Harvard Business Review. $\quad$ Retrieved from https://pdfs.semanticscholar.org/8c8a/55409a0bfd9d25ff7a453cb75d5b29321009.pdf

Reay, T. (2014). Publishing qualitative research. Family Business Review, 27(2), 95-102. https://doi.org/10.1177/0894486514529209 
Sacomano, M., Neto, \& Iemma, A. F. (2004). Estratégias e arranjos produtivos da indústria automobilística nos mercados emergentes: $\mathrm{O}$ caso brasileiro. Revista de Administração da UNIMEP, 2(3), 127-139. https://doi.org/10.1177/0894486514529209

Saes, M. S. M. (2009). Estratégias de diferenciação e apropriação da quase-renda na agricultura: A produção de pequena escala. São Paulo: Annablume, Fapesp.

Sanches, P. L. B., Machado, A. G. C. (2014). Estratégias de inovação sob a perspectiva da Resourced-Based View: Análise e evidências em empresas de base tecnológica. Gestão \& Produção, 21(1), 125-141. http://dx.doi.org/10.1590/S0104-530X2014005000005

Silverman, B. S. (1999). Technological resources and the direction of corporate diversification: toward an integration of the resource-based view and transaction cost economics. Management Science, 45(8), 1109-1124. https://doi.org/10.1287/mnsc.45.8.1109

Suddaby, R. (2010). Editor's comments: Construct clarity in theories of management and organization. Academy of Management Review, 35(3), 346-357. http://doi.org/10.5465/AMR.2010.51141319

Sörensen, D. (2006). The automotive development process: A real options analysis. Wiesbaden: DUVGabler Edition Wissenschaft.

Suddaby, R. (2010). Editor's comments: Construct clarity in theories of management and organization. Academy of Management Review, 35(3), 346-357. http://doi.org/10.5465/AMR.2010.51141319

Tebboune, S., \& Urquhart, C. (2016). Netsourcing strategies for vendors: A resource-based and transaction cost economics perspective. Journal of Information Technology, 31(1), 32-47. https://doi.org/10.1057/jit.2015.20

Teece, D., Pisano, G., \& Shuen, A. (1997). Dynamic capabilities and strategic management. Strategic Management Journal, 18(7), 509-533. https://doi.org/10.1002/(SICI)10970266(199708)18:7<509::AID-SMJ882>3.0.CO;2-Z

Toledo, J. C. de, Silva, S. L. da, Alliprandini, D. H., Martins, M. F., \& Ferrari, F. M. (2008). Práticas de gestão no desenvolvimento de produtos em empresas de autopeças. Revista Produção, 18(2), 405422. http://doi.org/10.1590/S0103-65132008000200015

Torres, R. L., \& Cario S. A. F. (2012). A governança da cadeia global de valor na indústria automobilística: Um estudo de caso. Revista Econômica, 14(1), 73-91. Retrieved from www.revistaeconomica.uff.br/index.php/revistaeconomica/article/download/40/42

Wernerfelt, B. (1984). A resource-based view of the firm. Strategic Management Journal, 5(2), 171180. https://doi.org/10.1002/smj.4250050207

Williamson, O. E. (1975). Markets and hierarchies: Analysis and antitrust implications. New York: Free Press.

Williamson, O. E. (1985). The economic institutions of capitalism: Firms, markets, relational contracting. New York: Free Press.

Williamson, O. (1991). Strategizing, economizing, and economic organization. Strategic Management Journal, 12(S2), 75-94. https://doi.org/10.1002/smj.4250121007

Williamson, O. E. (1996). The mechanisms of governance. New York: Oxford University Press.

Williamson, O. E. (1999). Strategy research: Governance and competence perspective. Strategic Management Journal, 20(12), 1087-1108. https://doi.org/10.1002/(SICI)10970266(199912)20:12<1087::AID-SMJ71>3.0.CO;2-Z 
Vanalle, R. M., \& Salles, J. A. A. (2011). Relação entre montadoras e fornecedores: Modelos teóricos e estudos de caso na indústria automobilística brasileira. Gestão e Produção, 18(2), 237-250. Recuperado de http://www.scielo.br/pdf/gp/v18n2/02.pdf

Yin, R. K. (2005). Estudo de caso: Planejamento e métodos (3a ed., D. Grassi, Trad.). Porto Alegre: Bookman.

Zylbersztajn, D. (1995). Estruturas de governança e coordenação do agribusiness: Uma aplicação da nova economia das instituições (Tese de livre docência), Departamento de Administração, Faculdade de Economia, Administração e Contabilidade, Universidade de São Paulo, São Paulo, SP, Brasil.

Zylbersztajn, D. (2009). Papel dos contraltos na coordenação agro-industrial: Um olhar além dos mercados. In J. P. de Souza \& I. N. Prado (Orgs.), Cadeias produtivas: Estudos sobre competitividade e coordenação (2a ed., pp. 38-74). Maringá: EDUEM.

\section{Autores}

Cleiciele Albuquerque Augusto

Av. Colombo, 5790, 87020-900, Maringá, PR, Brasil.

E-mail: cleicielealbuquerque@yahoo.com.br

José Paulo de Souza

Av. Colombo, 5790, 87020-900, Maringá, PR, Brasil.

E-mail: jpsouza@uem.br

Silvio Antonio Ferraz Cario

Rua Engenheiro Agronômico Andrei Cristian Ferreira, s/n, Trindade, 88040-900, Campus Reitor João David Ferreira Lima, Florianópolis, SC, Brasil.

E-mail: fecario@yahoo.com.br 